\title{
On Musicians' ears
}

\section{MISS Miriam A. Ellis}

To cite this article: MISS Miriam A. Ellis (1900) On Musicians' ears, Proceedings of the Musical Association, 27:1, 171-195, DOI: 10.1093/jrma/27.1.171

To link to this article: http://dx.doi.org/10.1093/jrma/27.1.171

$$
\text { 曲 Published online: } 28 \text { Jan } 2009 .
$$

Submit your article to this journal ㄴ

Џll Article views: 8

Q View related articles ¿ 
MaY 14, 1901.

THOMAS LEA SOUTHGATE, Eso.,

In the Chair.

ON MUSICIANS' EARS.

By Miss Miriam A. Ellis.

I HAVE been_asked to add further details of my observations of musicians' ears, together with some of the statistics I have gathered. It will be best to place these details first, as an introduction to this new subject.

The outer ear has long been used for the purposes of identification of criminals. M. Alphonse Bertillon's book, "Identification Anthropométrique," contains directions for the measurements of the ears, and divides the parts to be noted into the helix, the anti-helix, the tragus, the antitragus, and the lobe. Every ear differs, so that it has been found very difficult to reduce the rules to a practical form. The system has been adopted in England.

Having observed the ears of the upper educated classes, and studied Lavater's extremely vague surmises, it occurred to me to classify these " non-criminals" by means of natureprints of the ears. Mr. Francis Galton-whose fingerprinting method I adapted to the purpose-then brought M. Bertillon's book to my notice. But I found that the "non-criminals" had better developed ears than the criminals, and I had to mark off the helix, or rim, into more divisions, in order to identify them properly. Some of the results that $I$ obtained were given in a paper read before the British Association in 1898 , at the Bristol meeting. These have now been embodied and illustrated in my book, "The Human Ear: its Identification and Physiognomy" (Adam and Charles Black), published last December. Through friends, I had exceptional opportunities of obtaining earprints of those engaged in various professions and of high attainments, and $I$ noticed that the ears of musicians 
differed from the others in having a width of concha that interfered with the usual oval shape of the pinna.

The late Sir John Stainer, Mus. Doc., gave me much kind help in studying ears of musicians, for which I shall always be grateful, and it was by his invitation (as President of the Musical Association) that I undertook this paper. Outlines of his ears are in my book, as an example of the musician's ears. All the musicians he pointed out to me had the width of orifice I had observed elsewhere. Sir Walter Parratt, having a long oval ear, might seem an exception, but on measurement it will be found that the orifices are very much wider than usual in this form of ear, especially in the left ear, which is the orifice I always find slightly the widest in musicianly people. I should warn oval-eared persons that they have a greater chance of deafness than others, and should take more care of their ears, as the narrowness of orifice gives notice of weakness of the auditory nerves, and internal parts that assist the hearing.

The powers of hearing are well known to reside in the inner ear, and this being the case, physicians are apt to overlook the contour of the outer ear, while physiognomists have been content with the wildest conjectures, culled from the ancients and from Lavater's more modern researches. Many of Lavater's outlines are more like oysters than ears, and he had no system of comparison. It is just a hundred years since Lavater's death, therefore he had no photographs for collation. Nature-prints are as useful as photographs for comparing the size and shape of the helix, lobe, and orifice, and the illustrations to this paper are all made from natureprints (except Figs. 1, 3, and 9), taken by myself direct from the ear in each case, with the outlines afterwards traced in ink.

Since the shape of the outer ear indicates the kind and strength of the powers of hearing possessed by the inner ear, it is certainly worthy of careful note. There are several special forms of the orifice which appear to indicate the native powers of hearing music and of producing it. It is true that musıcians cannot be had without the proper training, but how often this training is wasted on the unmusical and withheld from those who could profit by it! The ears of infants are well formed with the orifice of a distinct shape, and I have observed the musician's form in those of a few weeks old, as well as in those of a few months or years. In each case the child showed its pleasure in music. As the face grows, the nose lengthens, and the ear enlarges even more rapidly, and I have noticed that the helix, or rim, alters from time to time, although, as far as I have been able to observe, the orifice appears to remain the same. When the ear has attained the length that the nose will have when full grown, it stops 
growing, apparently at about six to fourteen years of age. As it outstrips the rest of the face in growth, children are noticed for big ears. Perhaps, the saying "Little pitchers have long ears," has a physiognomical foundation! The shape of the orifice will therefore guide the parent in choosing a musical training for the child. Grinding-organs, mechanical pianos, and musical boxes should be kept from children who have really wide orifices, as such monstrous music inflicts unthought-of hardships upon such a child. Although I have never had the care of children, I have always been interested in education, and in watching their development my friends have frequently asked what I noticed and given me careful assent.

We must now describe the different kinds of musicians' ears. The ordinary kind of wide orifice is three-quarters the width of the whole ear at that part, and indicates excellent powers of hearing. The wide inlet between the tragus and anti-tragus seems to indicate quickness of hearing whole chords and distinguishing between sounds heard at the same time. Pianists, organists, and conductors of large orchestras usually possess these forms when they are very efficient performers and leaders. When there is a wide orifice with a rather narrow but very long inlet, single sounds seem to be the chief delight, and violinists often have this form-e.g., Paganini (see Fig. 9), also noted opera singers. For portrait examples, with the ears shown side-face, of pianists, organists, violinists, and opera singers, see the Musical Courier (1 895-97), and for conductors of varying degrees of celebrity, see "The Year's Music" (1899). Amongst amateurs, a delight in singing, or in hearing the singing of birds and human voices, rather than a delight in instrumental music, is very common where there is a moderate orifice and a narrow inlet. (See the Member of a Choir, Fig. 7.)

When the base-line of the orifice is rather straight, great acuteness in the hearing of high notes is possessed by the inner ear, independently of these being musical notes or not. With a very narrow orifice and long, narrow inlet, this power of hearing high notes is practically unlimited. (See Fig. 13.) The owner of these ears is quite unmusical, but has heard the highest notes ever offered by science as a test of the human powers. This peculiar power is also found so often among composers, that whenever a certain straightness of outline occurs in the other forms, we may expect to find a potential composer in the owner of the ear, if not one already known to fame. (See Figs. 3, 4, 5, 6.) Amongst noted organists whose sacred music has become known, this straightness is often in a slanted form, to permit of the wide orifice running right into the wide inlet. The point of the anti-tragus appears to be nearly smoothed off, in fact. 
There are, of course, composers without this form, but on further examination it will be found that this is due to the other qualities of the musician being so accentuated that the power of hearing acutely high notes is not the special point in their nature. The inlet in composers' ears is, however, generally short and wide, and somewhat slanted.

Where the inlet is both wide and long and goes nearly straight down, there seems to be an inner capacity of the owner to accept musical sounds and to reproduce them with marvellous facility on the piano or the organ. This is a special power, and, unless the orifice is wide also, it may exist without original powers. These pianists do indeed usually compose also, but their compositions are unconsciously echoes at best, if not plagiaristic. But with a wide orifice, the performers will often compose very agreeable original music.

Liszt had a very wide right ear, straight at the base of the orifice, with a point marking the place where the end of the inlet came under the tragus. He generally wore his hair over his ears, but in one of the portraits from a photograph in the Musical Courier (November 18, 1897), the hair is nearly off the lower part.

Wagner's right ear was wide, and the orifice was curved at the base, showing a moderately wide short inlet.

Sir Frederick Bridge's left orifice is very wide, and the base is nearly straight, going into a wide inlet that ends in a point, almost level. It is the typical organist-composer's orifice, of the best kind.

Brahms's left orifice was very wide, and rounded at the back and base, with a moderately wide and long inlet, slanted upwards till the lowest part is level with the base of the orifice.

Chopin's right orifice was wide and gently curved at the base, the inlet short and wide, its end level with the base of the orifice in the way seen in many of the celebrated composers.

Meyerbeer's left orifice was rather wide, with a nearly straight base, and a long narrow inlet, slanted like Sir Walter Parratt's.

Schubert's right orifice was wide and rounded, with a short wide inlet, slanting downwards. This is in a portrait from a painting, and seems badly drawn.

Most of the ears in the older engravings vary too much to be relied upon, but in the case of Mozart there is a certain resemblance amongst the best portraits. I have examined about a dozen, and even in childhood the wide ear is shown. I have taken the orifices from the most authentic pictures, and as they are undeniably of the musician's shape we may accept them as probable. (See Fig. 3) 
I have consulted numerous photographs of savage races as well as of civilised ones, and where the ears are not disfigured by native custom, the shapes were as individual as any others. The width of the ear follows the width of the outline of the profile of the jaw, and its length follows that of the nose from between the eyebrows to where the nostrils meet the upper lip. The negroes have wide ears and are counted musical.

Some terra-cotta votive ears, belonging to Roman days, are at the University Museum, Oxford, and others are at the Bristol Museum. They appear to be carefully moulded portraits of the once-afflicted ears. Every one of them suffers from a small or a narrow orifice, carrying out my suggestion that small or narrow orifices go with weaker inner powers of hearing than where the orifices are wide. The modern votive ear-tablets of silver or wax are manifestly made by the score for sale, and the orifices are fancy articles altogether, except where some artistic effort has been made to obtain a handsome ear as a genuine model for customers.

It would be convenient to have some clue to the native powers of the inner sense both for hearing and for music, and the shape and width of the orifice will be found very useful if both ears are carefully studied and collated. But nothing in the course of training the musical powers appears to have any effect on the shape of the orifice, which only indicates the kind of native inner sense of hearing and whether it is naturally capable of receiving musical training and in what direction this will be the most successful. Where the left orifice is the best shaped and the widest, the training will take the longest and will produce the best musicians. Where the right orifice is the largest and the best formed, there will be great facility in youth, and by judicious training enough knowledge and practice can be got to obtain success ; but something will certainly draw these people aside from their path after a time, because the powers of musical attention will wane of themselves, sufficiently to allow them to be distracted to other pursuits. In some cases the performer has become a teacher, a manager, or a director, withour being also a conductor. I have tested these three kinds of careers in portraits and biographies over and over again. I have also observed that my amateur musical friends gradually become more or less musical after five-and-twenty, according to the relative shapes of their two ears.

A word must be said as to heredity in the shapes of ears, a subject fully treated of in a chapter of my book, and which I first brought into notice at the British Association (1898). One orifice of one parent will be repeated in the opposite ear of one of the children, and one orifice of the other parent will 
be found in the same child's other ear. It is generally the eldest child that "takes after" both parents in this remarkable way. If the mother has wider or narrower ears than the father, the ears of most of the children appear to be modified in form by hers. I must refer readers to my book for numerous illustrations, as it can be easily consulted in the Reading Room of the British Museum. There is nothing in the shape or size of the ear or the orifice to show race or sex ; it is simply in proportion to the length of the nose and the shape of the jaw, as I have mentioned before.

I subjoin an analysis of a hundred ears, taken from the Musical Courier (1895-7), wherever the portraits are directly reproduced from photographs. I have only been able to obtain one ear in each case, therefore these are literally a hundred ears, not a hundred pairs of ears. They represent musicians of varied nationality and celebrity, but for obvious reasons I have not given their names:-

4 Composers.

22 Pianists.

23 Singers.

Io Violinists.

29 Organists.

9 Conductors.

3 Specialists (I flautist, I harpist, I mandolinist).

I00 Ears of Musicians.

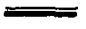

\section{Orifices.}

76 wide ( 28 were very wide); 24 moderately wide.

\section{INLETS.}

59 wide ( 28 were very wide); 25 moderately wide; 16 narrow.

\section{General Deductions.}

Composers have very wide orifices and generally very wide inlets.

The best pianists have-very wide orifices and wide inlets.

Most good singers have wide orifices and narrow inlets.

Good violinists have wide orifices and narrow but very long inlets.

Organists have the orifice slanted into a wide inlet, pointed at its base.

Conductors have wide orifices and inlets of any of the above shapes. 
The rest of this paper is the part which was read for me by the Secretary of the Musical Association at the meeting of May 14, to whom my thanks are due for the trouble and interest he took in the matter. The illustrations are outlines taken from nature-prints (except Figs. 1,3 , and 9), and are analysed and shown to be examples of the various forms of musicians' ears, which differ according to their native capacities. I give it in the original form, as it shows I referred to the auditory nerves in the second sentence, merely claiming that the shape of the orifice "indicates " the powers of the inner hearing.

The average shape of the pinna, or outer ear, is somewhat oval, with a large lobe, and a moderate orifice or concha, which incline to width or narrowness according to the powers of hearing of the possessor. (See Fig. I.)

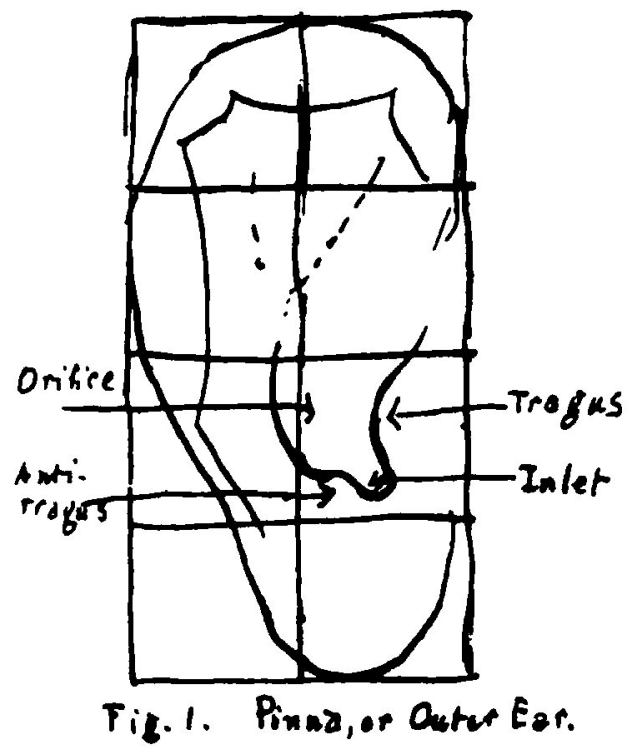

The shape and size of the orifice-the concha or hollow of the ear-especially indicates the powers of the auditory nerves, and the strength of the adjacent inner parts (the Eustachian tube and inner nostril) to resist deafness from cold, disease, or old age. The outline of the orifice is formed by the tragus and anti-tragus, and the inlet between them. (See Fig. I again.) 
A wide orifice pushes back the lower part of the ear and entirely alters the average oval shape, frequently shortening and widening the lobe. (See Fig. 2.)

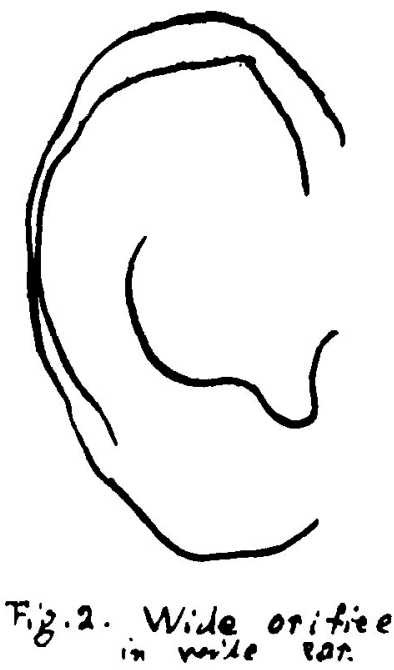

With this large wide orifice, a good power of hearnng seems always to be owned by the possessor of the ear. Such persons seldom become the least deaf until well over seventy or eighty. As ears are never exactly alike in a pair, there is always one ear slightly less wide in the orifice or in the inlet between the tragus and anti-tragus than the other, and it is sure to become the first to be "hard of hearing." Where the orifice, on the contrary, is narrow, slight deafness frequently begins even before middle life.

We must define a musician for our present purpose as a person who can distinguish between musical sounds, and can reproduce them, either by playing upon an instrument, or by singing, or by writing them down in accurate notation. Those who can distinguish musical sounds accurately without being able to reproduce them, may be called "potential" musicians, a term used on one occasion by the late Sir John Stainer. But the necessity of reproduction generally goes with the power of hearing these special sounds.

Music is widespread, and we must also define the wellknown English person who is "musical." A musical person is one who will listen to music with more or less pleasure, but will be unable to reproduce it in any way, however badly, and will require several "hearings" to recognise an 
easy tune. He will not distinguish between good and bad music-in fact, he will often prefer bad music because it does not require any attention. He will actually not hear the component parts of a chord, nor their inner progression, and will boast openly of his preference for what he calls " a good tune!" Classical music he calls "exercises," and says he prefers " real "music that has " something in it !" Amongst the lower classes, this musical person is fitly ministered to by the grinding-organ and the mechanical piano. The American organ is a more expensive variety of entertainment to such ears in co-operative workmen's clubs. Amongst the upper classes, a delight in a blatant brass band, where each instrument is out of tune with the rest, betrays the listener's incorrectly-shaped orifice.

The musician's ear has a wide orifice, with a large space between the tips of the tragus and anti-tragus. The inlet between the two latter is very short, and often slanted up until it is nearly level with the base of the orifice. (See Fig. 3. Ears of Mozart.)

\section{Right Ear}

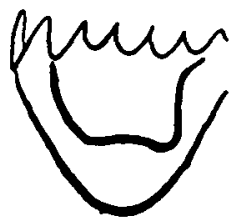

Fis.3. Mozart.

\section{Lefr Ear.}

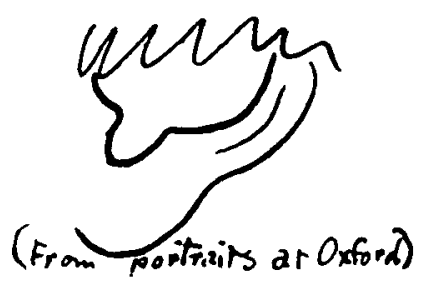

The two ears of Mozart show very beautifully the two forms of the musician's ear. They have been drawn from the best portraits at the Hope Collection of Portraits in the Bodleian Library at Oxford, and as they fit the face they are probably accurate. This is shown by the outline, which follows the outline of the jaw and chin, which are themselves of a shape that indicates that the ear must be wide The wig of the period hides the upper part of the ear.

We can prove that such ears could only belong to a musician by comparing them with those of the late Sir John Stainer. (I should mention that it was with his expresss permission that I give these outlines, together with those of his friends, Professor Sir Hubert Parry and Sir Walter Parratt.) (See Fig. 4. Ears of Sir John Stainer.) 
The orifice and inlet of the right ear correspond exactly with those of Mozart's left ear, and those of the left ear with Mozart's right ear.

A variation of form is found in the ears of Sir Hubert Parry. (See Fig. 5. Ears of Sir Hubert Parry.)

Both orifices are wide, but the inlet in the right ear is only of medium width, preventing full access of sweet sounds to that ear, and in the left ear the wide and shapely inlet points downwards instead of slanting upwards. This shows a limitation of choice of music, owing to a few gracious sounds being unnoticed in spite of great quickness of hearing.

A still more remarkable variety of form is shown in the ears of Sir Walter Parratt. (See Fig. 6. Ears of Sir Walter Parratt.)
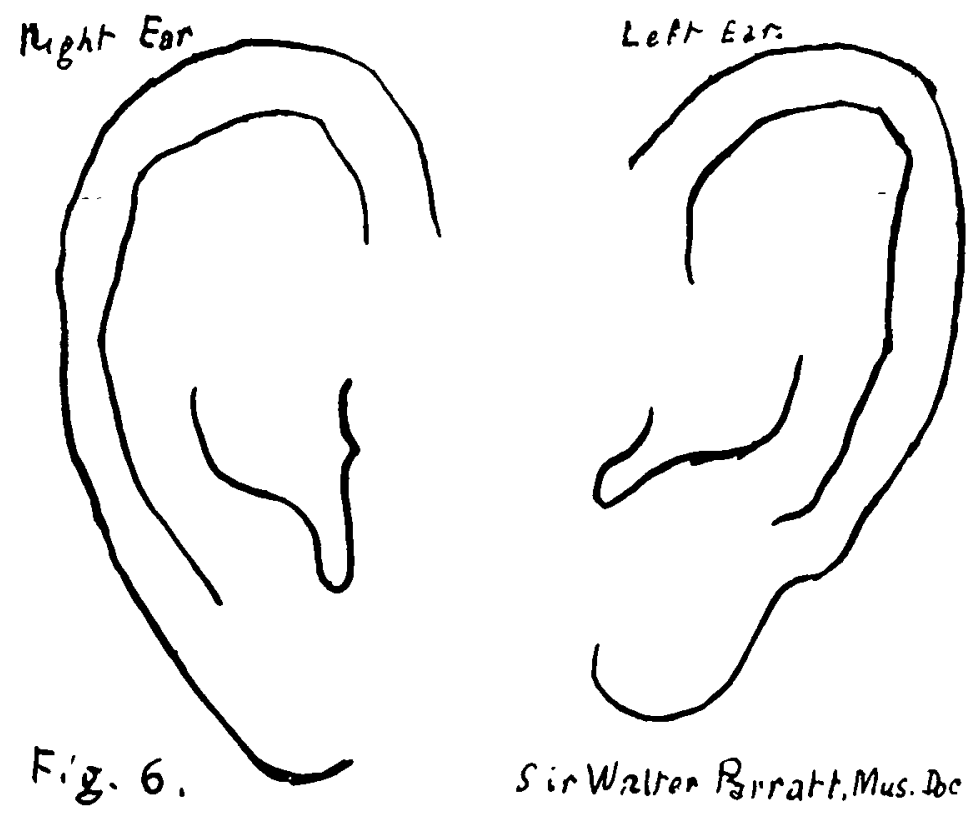

Sir Walter Borratt, Mus. Doc.

The ear is long and inclined to be oval, yet the orifice is wide in proportion to the ear; and though the inlet is long and narrow, yet the top is somewhat wider. In the left ear the inlet slopes up so much that the whole ear is slightly widened to make room for this shape, and the point of the anti-tragus is a mere curve, whilst the base of the orifice is nearly flat. This gives acute hearing for musical sounds, whilst other sounds are disregarded, as there is not enough "hearing" to spare for them. 
This long narrow inlet is seen in vocalists. (See Fig. 7. Ears of member of a large choir.)
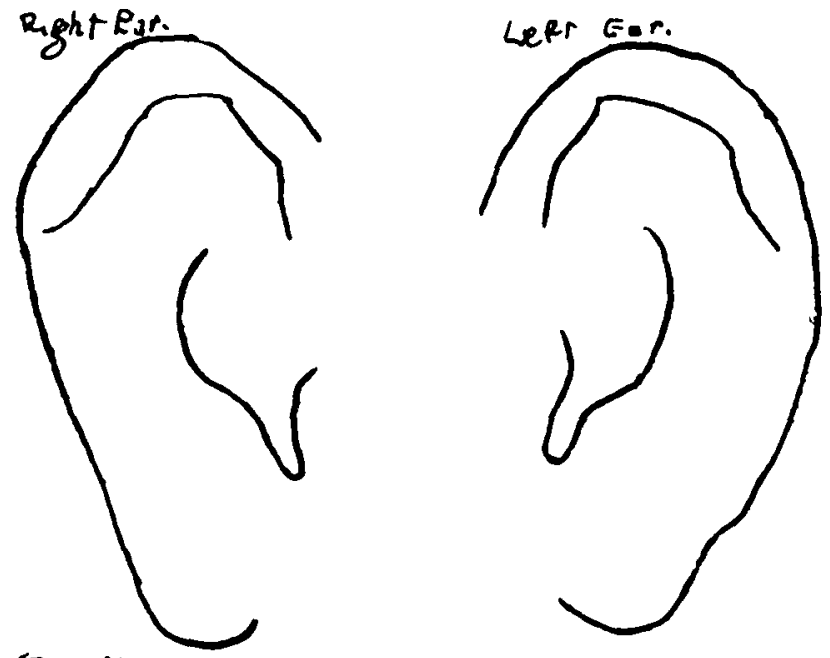

Fig. Y. nember of a large choir.

There is a sort of likeness in this left ear to Sir Walter Parratt's right ear, but the orifice is not so wide. It belongs to a singer in a large choir. Another member of the same choir possesses entirely different ears. (See Fig. 8. Ears of second member of the choir.)
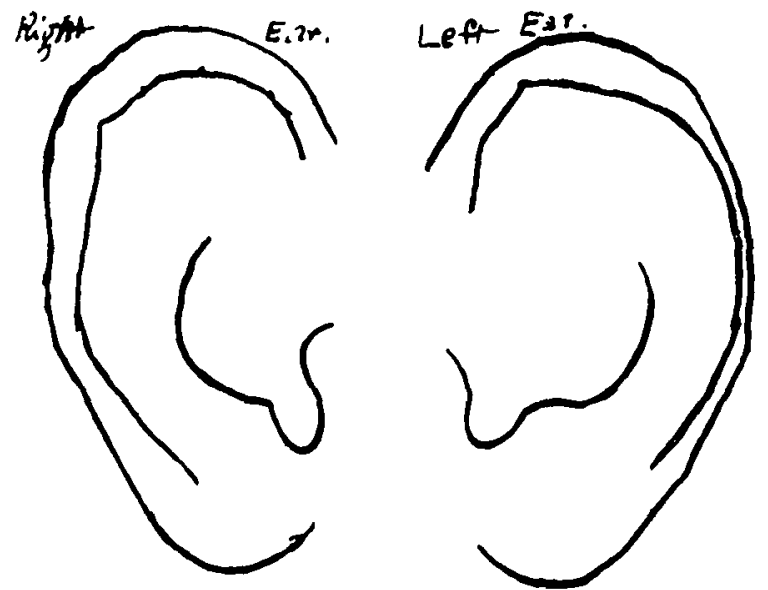

Fig. 8. Second mem ber of the ehoir. 
The left orifice shows the nature of a musician, but the right orifice counteracts it by being so much narrower, whilst the inlet, though wide, goes nearly straight down-it is therefore likely that singing would take the place of instrumental performance, as being easier to an amateur.

In a careful profile portrait of Madame Alboni, the renowned singer, the lower part of the ear is shown. The orifice is very wide, but the inlet is narrow, though as it slopes up nearly level with the base of the orifice, the whole ear gains in musicianly power. Perhaps that was the secret of the extraordinary charm of her singing, which sounds otherwise incredible as handed down in history.

A wide orifice sloping suddenly into a short wide inlet, is found often among organists and professional pianists, according to modern photographs. Where the inlet is not so wide, stringed instruments seem preferred. But wherever the musician is also a composer of agreeable and successful music, the base of the orifice is generally found to be rather flatter than in those who are only, or chiefly, performers.

Paganini was a marvellous performer, and if we can trust the portrait, his ear would bear this_out. (See Fig. 9. Orifice of ear of Paganini.)

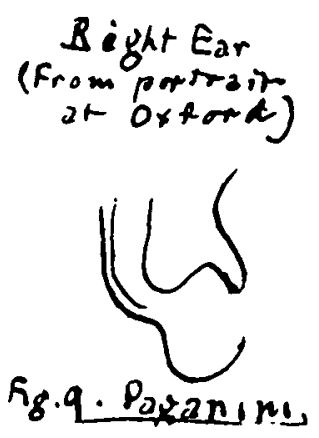

The narrow inlet is raised so high that its point is level with the base of the orifice, in the way that the wide inlet often is in good composers. We cannot be certain that his ear is rightly drawn, but such a shaped orifice is not to be seen in any other portrait of the many thousands $I$ have examined, so that we may give it the benefit of the doubt. Paganini's ears must have been as extraordinary as this one, in any case.

Among those who enjoy good music and attend concerts frequently, without being more than the merest amateur performers or singers, will be found a pretty rounded form of orifice and a rather narrow inlet. (See Fig. ro. Ears of a concert-goer.) 
Here the right orifice being less wide than the left and the inlet narrow, music was pushed aside, in this case by a Quaker up-bringing. In middle life the scruples being removed on the owner joining the Church of England, the left ear was allowed to indulge in its delight in music, although performance was now impossibe. The owner of this wide orifice and wide inlet especially enjoys classical music, and dislikes bad music without knowing why. She also has as good hearing in this ear as in her youth, though the other is very slightly touched by advancing age.

When the line of the base of the orifice is almost flat there seems to be particularly acute hearing. (See Fig. 12. Ears of an aged amateur musician.)
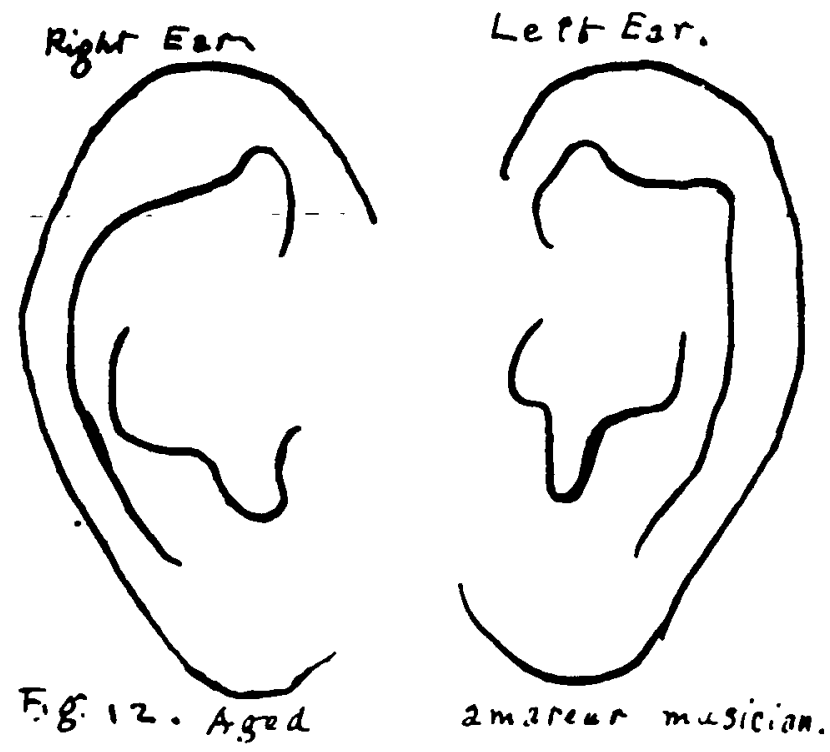

These are the ears of an amateur musician, whose hearing, at over eighty years of age, is still more acute than that of most young folks. The right orifice is that of a musician, the left is also wide, but the long straight narrow inlet betrays the amateur, whilst the straightness at the base of the orifice shows the painfully acute hearing.

An absolutely unmusical person ought, by this code, to have narrow orifices and very narrow inlets. If the base of the inlet is straight, the hearing should be acute for high sounds. I have been fortunate in obtaining the shape required, and the owner, who can hear exceptionally high 
acute sounds, does not like music. (See Fig. 13. Ears of an unmusical person.)

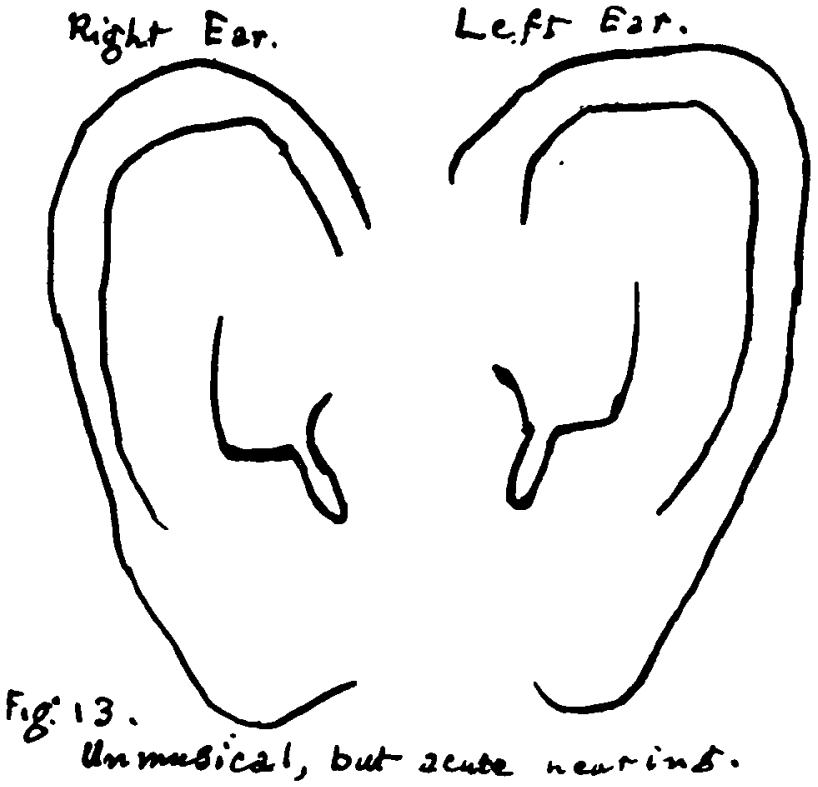

I have also met with another case, not quite so pronounced, where the owner prided herself on being able to hear the bat's cry, and she assured me that ninety-nine per cent. could not hear it. In this I think she is mistaken, as even musical persons can hear it, and musicians do not find the particular pleasure in hearing that shrill squeak which the unmusical appear to obtain from it.

It is well known that people frequently hear differently with each ear, and this bears out the suggestion I offer in this paper that the shapes of the orifice and the inlet indicate different powers of hearing.

It would be well to take special care of an ear with a narrow orifice (as of the sight of a weak eye), as the hearing is more liable to suffer on that side from chance injury or cold. I may mention that the amateur musician of eighty was once for two or three days suddenly deaf. The cause was over-fatigue of her nervous system, and, with proper remedies, her hearing returned as acute as ever. If she had known that a narrow inlet indicated a predisposition to over-fatigue of the auditory nerves, she would have been able to avoid that transitory deafness. It would be valuable to our young singers, who more often have narrow inlets than 
wide ones, to know how to take care of their hearing. I have not been able to obtain any authentic picture of Beethoven's ears, but perhaps the inlet of his left ear was of this narrow kind, for it is said that his deafness arose from having worn out his auditory nerve. In one of his letters he said he had heard so much more acutely than other people, that he seemed surprised his hearing should fail him. As the outline of the ear corresponds with the outline of the jaw and chin, as I have already had occasion to mention, we can surmise Beethoven's ear was wide, with an orifice that had a straight base. I have noticed that where both the inlets are wide and rather short, the hearing is strong up to extreme old age.

There does not seem any reason for one ear being different from the other, and still less reason for the following deductions I have drawn from practical observation. In right-handed people, I find the right orifice shows the kind of way in which they will regard music at first, and the left orifice will show how music will be regarded and carried out by them in the rest of their lives. We must all know excellent amateurs whose orifices are of unequal kinds, and musicians_who-cannot -take-the-high-place-their talents deserve because of hindrances to instruction in youth. Like soldiers, who must be of a certain height, musicians must have orifices of sufficient size to be successful in their warfare with life for the capture of sweet sounds.

\section{DISCUSSION.}

The Chairman.-Ladies and gentlemen, I do not know why, unless by accident, I should find myself in the chair on this occasion, because I have certainly no claim to a special knowledge of the subject. There is, however, one thing that I have noticed, and that is how very considerably the shape and contour of people's ears differ. Perhaps you do not notice, until possibly you have your attention specially directed to it ; but after this meeting, you will, I dare say, be looking at your neighbours' ears and then will notice how they differ in size and shape, and how far back some are set, and so on; I have drawings before me showing this much. I am happy to see and notice that, curious as the various shapes and sizes are, at least it can be said that musicians' ears are neither long nor pointed. There are probably some here who may have something to say on the subject, and I hope we shall have an opportunity of discussing the matter. I see one distinguished doctor here-Mr. Lennox Browne-and I am sure you will be happy to hear what he has to say. But 
there are two or three things that have been stated on which I should like to offer a few remarks. First of all as to the potential capacity of musicians being judged by the shape of their ears. I must confess I have usually looked on the matter as one of natural gifts and of training rather than depending on the contour of the particular apparatus with which nature has provided us to hear music; but, perhaps, Miss Ellis will tell us if she considers it is not so. If that be so, and there are enough examples from which to form a safe deduction without drawing hasty generalisations, we might tell at once when children are born whether they have a chance of becoming musicians. What an advantage it would be! All the unfortunates who never do anything satisfactory beyond paying for their master's instruction could be brushed aside, and the promising ones could be sent to the R.A.M. or R.C.M.; no doubt we should thus get much better results than at present. If the shape of the ear helps us to determine this, then I think this paper will not have been written in vain. I see a drawing there of Mozart's ear. Of course, most persons who have read anything about Mozart's personal appearance, and those especially who have been to the Mozarteum at Salzburg must have noticed this. I always supposed this curious drawing to be an exaggeration; perhaps it is not, but it differs enormously from the general form of the ear. I should like to ask Miss Ellis, who I hope at the end of the discussion will have something to say to us, whether she has had her attention called to the ears of barbarous people-I mean people who cannot appreciate Bach's fugues, or Beethoven's sonatas, or Wagner's operasthe ears, say, of Zulus or Hottentots ; will she tell us whether there is this great diversity of shape to be found there as in the case of the civilised people she has examined? It certainly seems very curious to hear that as one grows the outer contour of the ear can be altered by anything that happens; but, as I understand the paper, theology has the power of altering the shape of the ear. If so, it would be very desirable to determine with certitude just which is the right and proper kind of religion, and then we might have our ears properly and theologically shaped accordingly. With regard to the limits of hearing, so far as I remember the lectures that were given many years ago, when I was quite a young man, by Tyndall at the Royal Institution, I think he showed that the limits of hearing depend on the larger or smaller number of the Corti fibres, which vibrate in unison to the pitch of the various sounds we hear. I think I can remember an illustration which Tyndall gave. He had a siren, which was set going on a very low note, and he said, 'As the sound rises I want anyone who is no longer able to hear the sound to hold up his hand. After a time an individual in the 
company held up his hand, though the rest of us could still hear. Later on others and others held up their hands, and at last the note became so high that I too was deaf to the sound ; but there were some who could hear still higher notes. Perhaps someone will tell us whether this power of hearing is determined by the apparatus inside our ear, or by the outside contour. Then as to deafness; if I rightly understand the paper, it seems that though deafness may arise from various mechanical injuries or from cold, it also in a measure depends on what happens to the outside portion of the ear, as well as to the complicated apparatus inside. I should like to know whether I rightly appreciated that or not. Now, before calling on Miss Ellis for her reply I will invite discussion; and first should like to hear what Mr. Lennox Browne, who is a distinguished aural surgeon, has to say on the subject.

Mr. LeNNox Browne.- It is quite true that I am not now a member of this Association, but I am happy to say I was an original member and a regular attendant for some years. I remember Mr. Ellis, to whom educators and musicians alike are so much indebted. Consequently, when I received an invitation to hear a paper from Miss Ellis, I gladly availed myself of the opportunity. I must, however, speak as I am inspired, and I am sorry to say I disagree with the author in toto. In art we must speak what we feel to be right, and neither hard nor soft words will alter facts. The very premisses of the communication are novel to me. I have always believed that the outside ear is simply a receiver, the middle ear the conveyer of sound, and the inner ear, to which you, Mr. Chairman, alluded, and your remarks were perfectly correct, is the chamber in which is situated the auditory nerve, that is, the nerve of special sense. The fact is, that really until this evening I have never heard of any anatomical difference in the shape of the external ear of any musician, whether a composer, instrumentalist, or vocalist, any more than we can find anything distinctive in the vocal chords of a singer. I have had the opportunity of seeing the vocal chords of Tietjens, Patti, Melba, and hosts of others. I believe there are some imaginative doctors, especially in the "gay city," who can tell whether a person has a singer's voice and even the range and quality by looking at the vocal chords. I have never seen it myself, nor do I believe there is any such difference.

The Chairman.-I should be glad if Mr. Lennox Browne would go on to tell us whether an examination, not only of the vocal chords, but of the other parts of the throat, such as the soft palate, would give any indications of the prospect of that particular individual becoming a singer.

Mr. Lennox Browne.-As an answer to your question, Sir, I would say that I remember having a very wonderful girl 
brought to me from Florida, a child who, it was supposed, was going to be another Patti. I said, so far as the throat is concerned, "There is no reason why she should not, but there is not the least reason that I can see why she should." When you come to the soft palate you come to muscles that are under control, and I remember that Mrs. Weldon, who, with ill her eccentricities, was a very wonderful woman, in criticising a lecture of mine said, "You must get the soft palate of a singer as hard as a bone; the soft palate is the biceps of the voice which must be hardened." But you do not find any alteration in the vocal chords. In the same way I should say with regard to the eyes of painters, though I believe the blue eye characterised Turner, William Hunt, Millais, and a number of other living painters, noted as colourists; still there are many fine colourists who have not blue eyes. So I say there may be something in Miss Ellis's contention in the peculiarities of the external ears of these great composers, but I do not think it had anything to do with their being musicians, because I think you would find these conditions in people who are not musicians, and many musicians whose ears did not conform to Miss Ellis's type ; certainly with regard to the inequality of the ears. Though we are supposed to be symmetrical beings, as a matter of fact we are not. There is hardly a person living in the civilised world who is perfectly symmetrical in features-especially in the nose, for example. There are many people who have a symmetrical soft palate, and symmetrical ears and eyes ; but I certainly have never cared much whether the ears were symmetrical or not, because we look inside the ear, and rarely, except in the case of deformities, look at the outside. Although I can hardly admit that I should have been more convinced of the accuracy of Miss Ellis's views as to the influence of the shape of the external ear, her remarks would have carried more weight could we have seen photographs of the actual ear instead of rough diagrams from paintings or models. For instance, the man who took Paganini's likeness probably paid but little attention to the details of his ears. The ear is a feature particularly neglected by painters-more than any other part of the face-and it, to my mind, quite spoils a portrait to see the careless way the ear has been dashed in; so that these old engravings are not to me of the value they would have been if they were photographs or models. You have to consider the ear from the position of the instrumentalist or composer. The moment we speak of a composer we think of Beethoven; Miss Ellis alluded to him. Beethoven is supposed to have had three periods. His last I have read was crude, hard, and unsympathetic because of his deafness. On the other hand, many modern critics regard this last period as his 
most mature and most perfect. I have heard he did not write well for the voice because he was deaf; but I have heard the same of Wagner, who was not deaf. Certainly the whole history of Beethoven shows that the musician's ear is something that cannot be analysed; it is an impalpable gift bestowed by the Almighty, and not dependent on any physical consideration of the outside ear. As to the ear of the instrumentalist, in the paper I read on "The Voice as a Musical Instrument " before this Association a quarter of a century agoI am not sure, Sir, whether you were present, but I remember several now present who were-I recommended for the training of the voice that singers should play a stringed instrument in order to train the ear, and it is a curious thing that it is the stringed instrument players who most of all are liable to suffer in the performance of their work from deafness. Their case is very similar to that of a sportsman, who will often get deaf in the ear that is most exposed to the barrel side of his gun. Players on wind instruments are much more liable to suffer from affections of the throat or chest, but I remember a case in one of two flautists who played side by side. He told me he was constantly getting the note of his colleague's part into his ear, and that this interfered with his perception of his own part. In the case of the singer the importance of hearing correctly is very great, as you all know. If a singer sings flatter than he should, he may be simply out of condition ; but if he sings sharp it demonstrates an impairnent of the correctness of his perception. I had to translate a book written by a Frenchman on Deafness, in which he said there was a proverb that a man shouted like a deaf one. In my translation I put a note that that proverb was not known to Englishmen, and that a person deaf from what is called conduction usually speaks softly, because he hears sounds louder than they are ; while a person deaf from disease of his auditory nerve often speaks at a characteristically high pitch. This explains the remark about Beethoven that Miss Ellis made; he heard sounds with extreme keenness-what we call hyperacousis-and I have seen cases of musicians who have in their brain a musical phrase or sound-something perhaps of their own invention, which has troubled them just the same as noises in the ear will trouble the deaf people who are not musical. I have met many musicians who suffer from a highly sensitive nerve to certain sounds; that is the penalty I suppose of education. The following anecdote illustrates the importance of hearing to the singer. Mr. David James, the actor, had a very beautiful singing voice, but on one occasion he found it out of order. I discovered nothing whatever wrong with his vocal organ, but there was a high degree of deafness, caused by impacted wax. This removed, his voice was at once restored. A still more celebrated musician-a great conductor- 
known to all of us, came to me. Those acquainted with him are aware what a highly sensitive and impressionable man he is. He was in a state of despair. He said with great excitement his hearing was going ; he could not conduct his orchestra. I found the same cause. The patient on regaining his hearing almost threw his arms round me, saying that I had saved his life; but it did not prevent him from coming to me again six months after, in the same state of excitement, to be again relieved from the same slight ear trouble. There are several people who have a musical ear who are deaf to outside sounds. The late Lord Ernest Bruce was a great theatre-goer, but was so deaf that you had to shout in his ear; nevertheless, he could tell-at least he expressed the opinion-whether a singer was singing as well as usual or not. The tendency of my remarks you will see is to show that we must first know the full physiology of hearing, and then must remember that the condition of hearing depends not only on the health of the individual, but also on the health of the organ itself.

Miss Chamberlayne.-I should just like to add that since humanity was created there have been no two persons alike. There have been no two ears quite alike; so it may be impossible for two persons to hear alike.

Mr. WedmorR. - If I might be allowed to offer a few remarks regarding the physics of hearing, there are one or two points Mr. Lennox Browne made on which $I$ should like to say a few words. I was recently a demonstrator to Dr. Silvanus Thompson, and so am in touch with recent developments in this connection. I may say that the theory of Corti's fibres is open to revision. There are a few facts which do not agree with this theory, and there are opposition theories already formulated. The whole matter being not quite understood, any new views properly put forward in a scientific manner are likely to be of great value. I must say I was disappointed this evening to hear so many deductions and so few facts. If we have a person with a scientific reputation behind the deductions they may be accepted, but when the deductions are advanced without the facts, one is obliged to ask for the facts. If this view of a connection between the shape of the external ear and musical ability can possibly be supported by statistics-though I see no connection on physical grounds, and Mr. Lennox Browne has stated the same on physiological grounds-if the theory can be backed by statistics, it becomes of great value both to the physiologist and to the physicist. So I hope Miss Ellis will not be discouraged, but rather try to advance her theory in the way I have suggested. There are scientific magazines that would be glad to receive a statistical article on the subject. While I am on my feet I should like to ask if Miss 
Ellis can throw any light on a peculiarity of my own hearing which I have only recently discovered and which seems quite inexplicable. I am fond both of whistling and of playing the piano, and curiously my hearing for whistled notes is a fourth out with my hearing for piano notes. While my whistling, though a fifth high, sounds in perfect harmony to myself, and I can follow with facility complicated changes of harmony, the result to others is excruciating. Curiously too, I can whistle correctly above GI. I can play a note that is sung, or whistle a note that is whistled correctly, but I cannot whistle a note that is played or sung except by calculation.

Mr. Lennox Browne.-I fancy the compass of whistling corresponds to the compass of the voice. Perhaps our friend in whistling is beyond the compass of his singing voice.

Mr. WeDMORE.-I can whistle over three octaves.

Chairman.- I should like to say a few words on one or two remarks of Dr. Lennox Browne. I hardly think Miss Ellis would venture to say that for the three periods of Beethoven's work the shape of the ears was altered. With regard to some_of his_music_of_the_last_period, there_are_a good_many. musicians who think that though he could, of course, hear with his eyes, yet if he had afterwards heard with his ears what he had written he might have modified and re-written some of it. Now, has not ear-training very much to do with the whole of this question? There are persons musically inclined who like music just in an ordinary way to the end of their lives. But sometimes these persons are moved to listen to "good" music, then to take an interest in it, then to enjoy a modicum of culture, and, at last. to become enthusiastic musicians. Sir George Grove is an instance; he only liked music a little till he went to the Crystal Palace. You all know what a deal he did for music afterwards. Surely it was simply training and not an alteration of the ear in his case. A great many persons think that our musical system is perfect and.complete in all ways. I am not inclined to accept that position myself. You know that the systems of the Hindus and Arabs, and some other nations, include much smaller intervals in their scale of musical sounds than, ours, and they can detect differences of pitch that we hardly notice. The Indians employ something like twenty-two intervals in their octave. Is not this power merely a question of training? If we had been born in India, doubtless we could do it as well as they; whereas, being trained in European music, we measure it by European standards, and appreciate nothing else. I was struck by that remark of Mr. Lennox Browne about singing flat and sharp. That is my experience also. People sing flat when they are not well; but when they sing sharp they had better leave off - they are 
chronic ear invalids and are done for. As to hearing sounds or musical phrases in our head, it is quite common to hear singing in the ears. If one is not well we can hear in our heads, so to speak, all sorts of music. This clearly can have nothing to do with our ears; it is mental. Mr. Wedmore said truly that in trying to arrive at a conclusion in such a matter as this we want plenty of facts, actual photographs and statistics, because it is very unsafe to draw deductions from the ears of any one man, such as Beethoven, Stainer, Parry, or Mozart. We must get a large number of cases, and then we shall be able to judge whether a theory of outer contour is worthy of consideration. As has been pointed out, if we had had enlarged photographs we might have come to some conclusion as to how much and in what way the contour of the outer ear really has to do with music. I will now ask Miss Ellis to favour us with some remarks on what has been said on her paper.

Miss Ellis.-I should like to say that these pictures, with the exception of Figs. I, 3, and 9, were all taken direct from nature. So the facts there are really facts, and my deductions are the result of my going through hundreds of authentic pictures of ears for this paper, and very many thousands in the course of preparing my book, never finding one of $\mathrm{my}$ deductions fail. But I did not know you wanted statistics, or I could easily have given a paper on them. I have also studied the whole ear for many years past in relation to identification and physiognomy. It is not that the shape gives hearing; but it gives the indication of the kind of hearing. It is quite true that babies show at once whether they are musical or not. It is not easy to train the owner of an unmusical orifice to be a musician. As to hearing twenty-two musical sounds in the octave, I could always hear them without any trying, I suppose because both orifices and both inlets in my own ears are wide, and I have found this will indicate attention to all kinds of musical sounds. I have looked at photographs of all the nations in the world, and I find one cannot tell by the shape of an ear whether it belongs to any particular nation, because they vary according to the owner s particular powers. I have drawings of black and white and brown people. I did not know you wanted these facts; but I had collected them and made my deductions from them. I brought these specimens because they were striking illustrations of the subject; I thought they would show they had facts behind them. You often observe that a face is intelligent, though you may not know what particular details indicate the intelligence, and you treat your children in accordance with those indications. The ear is often not fully grown till about fourteen years of age. You can tell what kind of music a child 
will learn best by the indications afforded by the shapes of the orifices and the inlets. If the right ear is wider than the left they will get on much better with their music while they are young, but they may not stick to it; if on the other hand the left ear is wider than the right, they may seem slow while they are young, but they will develop later. These different forms do not seem to hear music in the same way. It is really a sort of physiognomical operation, and I have never known it to fail in a single case. I have looked through hundreds and thousands of portraits, particularly all the photographs I could find.

Chatrman.- I shall have to ask you now to move a vote of thanks to Miss Ellis. Her theory is that as the face is the mirror of the mind, so, if I understand rightly, the contour of the outer ear is the mirror of the internal mechanism with which musicians are specially gifted. May I suggest that in preparing her paper for our volume of "Proceedings," she enlarge it a little, and give us some more facts, together with tabulated deductions, and show how the ears of musicians differ from the non-musical.

Mr. J. Percy Baker.-It is only just to Miss Ellis to mention that before this meeting she, without knowing my particular branch of the musical profession, informed me that I had the "organist's ear." I am bound to say that her diagnosis was perfectly correct.

The vote of thanks was then passed unanimously. 